\title{
Adubação foliar de nitrogênio em capim mombaça (Panicum maximum cv. Mombaça)
}

\author{
Marizane Pietroski ${ }^{1}$, Reginaldo de Oliveira ${ }^{1}$, Gustavo Caione ${ }^{1}$ \\ ${ }^{1}$ Universidade do Estado de Mato Grosso - UNEMAT. Alta Floresta, MT, Brasil, E-mail: agro_pietroski@ hotmail.com; \\ reges23@outlook.com; gcaione@unemat.br
}

Recebido: 01/10/2015; Aceito: 26/10/2015.

\section{RESUMO}

A adubação nitrogenada proporciona incremento na produtividade das pastagens, sendo a aplicação foliar uma alternativa complementar. Assim, objetivou-se avaliar o efeito da aplicação foliar de nitrogênio $(\mathrm{N})$ na produção de forragem, acúmulo de N, proteína bruta e no índice de cor verde das folhas de capim Panicum maximum cv. Mombaça. O experimento foi realizado em uma propriedade rural situada no município de Nova Guarita - MT, Brasil. O delineamento experimental foi em blocos casualizados com quatro repetições. Os tratamentos foram constituídos pela aplicação foliar de cinco doses de $\mathrm{N}$ (0 (controle), 15, 30, 45 e $60 \mathrm{~kg} \mathrm{ha}^{-1}$ de N). Foram conduzidos dois ciclos, realizando-se a coleta da forragem para a determinação da massa de matéria verde e seca, teor e acúmulo de $\mathrm{N}$ na matéria seca e teor de proteína bruta $(\mathrm{PB})$. No último ciclo também foram realizadas as mensurações do índice da intensidade da cor verde da folha. A aplicação foliar de nitrogênio proporcionou aumento na produção de forragem, índice da cor verde, acúmulo de $\mathrm{N}$, sendo, portanto, uma importante prática complementar a adubação do solo. Houve incremento no teor de proteína bruta, atingindo valores acima do mínimo necessário para o consumo animal. A aplicação de $35,24 \mathrm{~kg} \mathrm{ha}^{-1} \mathrm{de} \mathrm{N}$ foi a dose de maior produção com $1.799 \mathrm{~kg}$ $\mathrm{ha}^{-1}$ de matéria seca.

Palavras-chave: Adubação nitrogenada, pastagem, produtividade de forragem, ureia.

\section{Foliar application of nitrogen on mombasa guinea grass (Panicum maximum cv. Mombaça)}

\begin{abstract}
Nitrogen $(\mathrm{N})$ fertilization promotes increase in pasture productivity, and foliar application of $\mathrm{N}$ can be a complementary alternative. The objective was to evaluate the effect of foliar application of $\mathrm{N}$ on forage production, $\mathrm{N}$ accumulation, crude protein and green color index of mombasa guinea grass (Panicum maximum cv. mombaça). The experiment was conducted on a farm in the municipality of Nova Guarita - MT, Brazil. The experimental design was a randomized block with four replications. The treatments constituted of foliar application of five $\mathrm{N}$ rates $\left(0,15,30,45\right.$ and $60 \mathrm{~kg} \mathrm{ha}^{-1}$ of $\left.\mathrm{N}\right)$. The mass of green and dry matter, $\mathrm{N}$ concentration and accumulation and crude protein content were measured in two cropping cycles. In the second cycle were also measured the intensity of green leaf color index. Foliar application of $\mathrm{N}$ provided an increase in forage production, green color index, $\mathrm{N}$ accumulation is therefore an important practical complement to soil fertilization. There was an increase in crude protein content, reaching levels above the minimum required for the animal consumption. The application of 35.24 $\mathrm{kg} \mathrm{ha}^{-1}$ of $\mathrm{N}$ was the rate of the higher forage production (1799 $\mathrm{kg} \mathrm{ha}^{-1}$ of dry matter).
\end{abstract}

Key words: Nitrogen fertilization, grazing, forage yield, urea. 


\section{Introdução}

O cenário das pastagens brasileiras é caracterizado em cerca de $80 \%$ em algum estágio de degradação (MELLO et al., 2008), sendo a perda da fertilidade natural do solo uma das principais causas desta situação. Neste contexto, destaca-se a deficiência de nitrogênio (N) como um dos fatores limitantes à produtividade das pastagens, sendo que, em caso de baixa disponibilidade no solo tem-se queda acentuada na capacidade de suporte e ganho de peso animal (ROCHA et al., 2002).

Mesmo as pastagens tendo elevados níveis de produção, o manejo inadequado do animal e a falta de reposição de nutrientes são os principais fatores que podem promover a degradação destas pastagens (MACEDO, 2009), comprometendo tanto sua qualidade quanto sua produtividade. Em pastagens o potencial de produção é determinado geneticamente. Porém, além desta característica genética são necessárias condições adequadas do meio e do manejo (FAGUNDES et al., 2006). Um exemplo é o capim Mombaça por pertencer a um grupo de forrageiras de alta produtividade e muito exigente em fertilidade do solo (SOUZA et al., 2005).

A adubação nitrogenada além de aumentar a produtividade (FAGUNDES et al., 2005) pode melhorar a qualidade da pastagem, incrementando o teor de proteína bruta $(\mathrm{PB})$ e melhorando a digestibilidade (MAZZA et al., 2009), reportando a importância deste nutriente para as plantas. Isto ocorre devido este nutriente ter função estrutural, pois o mesmo faz parte de moléculas de compostos orgânicos, como os aminoácidos e as proteínas, e exerce diversos processos metabólicos como síntese de proteína, absorção iônica, fotossíntese, respiração, multiplicação e diferenciação celular (MALAVOLTA, 2006).

A demanda pela adubação nitrogenada é alta, porém o capim Mombaça consegue apresentar grandes respostas na adubação, chegando a valores de $30.332 \mathrm{~kg}$ ha $^{-1}$ ano $^{-1}$ de matéria seca com a aplicação de $500 \mathrm{~kg}$ ha ${ }^{1}$ de $\mathrm{N}$ ao solo, sendo que na ausência de aplicação de $\mathrm{N}$ a produção é muito inferior (4.164 $\mathrm{kg} \mathrm{ha}^{-1} \mathrm{ano}^{-1}$ ) (MELLO et al., 2008). Neste caso, em que a dose de fertilizante é alta, a utilização de adubação foliar seria ineficiente para fornecer $100 \%$ do $\mathrm{N}$ aplicado, porém poderia ser uma alternativa complementar a adubação do solo.

Com a adubação foliar pode-se realizar a aplicação de fertilizantes diretamente em áreas de maior interesse, permitindo o fracionamento das doses e o aumento na eficiência da adubação. Trabalhos realizados com diferentes métodos de adubação afirmam que se pode ter maior eficiência de aproveitamento de nitrogênio com a adubação foliar, gerando um incremento de $26 \%$ na altura de plantas tendo um menor valor de perdas em relação ao aplicado via solo (DEUNER et al., 2008). Tais perdas são devidas à aplicação superficial a lanço de fertilizantes nitrogenados sem incorporação em pastagens tropicais, onde o $\mathrm{N}$ é perdido por meio dos processos de volatilização da amônia, desnitrificação e erosão do solo (CIVARDI et al., 2011), e a lixiviação do nitrato na situação em que o $\mathrm{NO}_{3}{ }^{-}$estando na solução do solo e não é absorvido pelas plantas ou quando imobilizado pela microbiota do solo, pode ser facilmente lixiviado, pois apresenta carga negativa e não é adsorvido pelos colóides do solo que apresentam predominantemente cargas negativas (PRIMAVESI et al., 2006). Essas perdas no sistema de produção geram impactos negativos no meio ambiente, como a contaminação do lençol freático e na liberação de $\mathrm{N}_{2} \mathrm{O}$, contribuindo no aquecimento global (MELLO et al., 2008).

Diante disto, objetivou-se avaliar os efeitos da aplicação foliar de nitrogênio $(\mathrm{N})$ na produção de forragem, acúmulo de $\mathrm{N}$, proteína bruta e no índice de cor verde da folha de capim Panicum maximum cv. Mombaça.

\section{Material e Métodos}

$\mathrm{O}$ experimento foi realizado em uma propriedade rural localizada no município de Nova Guarita, MT, situada a $55^{\circ} 17^{\prime} 9.94 "$ longitude oeste e $10^{\circ} 26^{\prime} 17.33^{\prime \prime}$ latitude sul, a $286 \mathrm{~m}$ de altitude. $\mathrm{Na}$ área experimental, estava sendo cultivada a gramínea forrageira Panicum maximum cv. Mombaça já implantada no local no período de dois anos e manejada sob sistema rotacionado. Não havia histórico de correção e adubação do solo.

Antes da instalação do experimento foram coletadas 15 amostras simples de solo na profundidade de 0-20 cm para compor uma composta. A análise granulométrica e química do solo na área experimental foi realizada seguindo a metodologia proposta pela Embrapa (2009), em que obtiveram-se os seguintes resultados: $\operatorname{argila}=429 \mathrm{~g} \mathrm{~kg}^{-1}$; areia $=433 \mathrm{~g} \mathrm{~kg}^{-1}$ e silte $=$ $138 \mathrm{~g} \mathrm{~kg}^{-1} ; \mathrm{pH}$ em água $=6,0$; matéria orgânica $=7,7 \mathrm{~g}$ $\mathrm{kg}^{-1} ; \mathrm{P}_{\text {(mehlich) }}=2,1 \mathrm{mg} \mathrm{dm}{ }^{-3} ; \mathrm{K}=0,11 \mathrm{cmol}_{\mathrm{c}} \mathrm{dm}^{-3} ; \mathrm{Ca}=$ $1,57 \mathrm{cmol}_{\mathrm{c}} \mathrm{dm}^{-3} ; \mathrm{Mg}=0,61 \mathrm{cmol}_{\mathrm{c}} \mathrm{dm}^{-3} ;(\mathrm{H}+\mathrm{Al})=3,48$ $\mathrm{cmol}_{\mathrm{c}} \mathrm{dm}^{-3} ; \mathrm{SB}=2,29 \mathrm{cmol}_{\mathrm{c}} \mathrm{dm}^{-3} ; \mathrm{V}=39,6 \%$ e $\mathrm{CTC}=$ $5,77 \mathrm{cmol}_{\mathrm{c}} \mathrm{dm}^{-3}$.

O delineamento experimental utilizado foi o de blocos casualizados, constituído por cinco tratamentos, sendo $0,15,30,45$ e $60 \mathrm{~kg} \mathrm{ha}^{-1}$ de $\mathrm{N}$, com quatro repetições. Cada unidade experimental apresentava $3 \times$ $5 \mathrm{~m}$, sendo desconsiderado $0,5 \mathrm{~m}$ em cada extremidade para as avaliações.

A área de pastagem, antes da aplicação dos tratamentos, foi aberta aos animais para o pastejo, sendo retirados quando a altura do capim atingiu média de 30 $\mathrm{cm}$. Depois de quatro dias após o pastejo, foi feita a aplicação dos tratamentos, utilizando como fonte de $\mathrm{N}$ a 
ureia (45\% de $\mathrm{N}$ ), sendo diluída em um volume de calda de $400 \mathrm{~L} \mathrm{ha}^{-1}$ e aplicada com o auxílio de uma bomba manual de $5 \mathrm{~L}$.

A aplicação dos tratamentos foi realizada no fim do dia 27 de dezembro de 2014 e, após 26 dias, quando as primeiras parcelas apresentaram altura de $90 \mathrm{~cm}$ foi avaliada a produtividade de forragem, realizando o corte do capim em uma área de $0,50 \times 0,50 \mathrm{~m}\left(0,25 \mathrm{~m}^{2}\right)$ por parcela, deixando o capim a uma altura de $30 \mathrm{~cm}$. Depois do corte, foi aberta a área durante um dia para o pastejo animal.

A forragem coletada foi levada para o laboratório, pesada e seca em estufa com circulação forçada de ar à temperatura de $65{ }^{\circ} \mathrm{C}$, até atingir massa constante e obtenção da massa seca. O material vegetal foi moído e utilizado para as determinações dos teores de $\mathrm{N}$, de acordo com a metodologia proposta pela Embrapa (2009). O resultado foi multiplicado pelo fator de conversão de 6,25, conforme sugerido por Jones (1931) para a obtenção do teor de proteína bruta. A partir dos dados de teores de $\mathrm{N}$ na forragem e a massa seca da parte aérea, foi calculado o acúmulo de $\mathrm{N}$ na parte aérea da forragem produzida.

Dez dias após o $1^{\circ}$ corte, foram aplicados novamente os mesmos tratamentos. Com 15 dias após a aplicação dos tratamentos e que as primeiras parcelas do capim mombaça atingiam $90 \mathrm{~cm}$ de altura, efetuou-se, em horário de alta intensidade luminosa, sendo por volta das 10:30 h (horário de Cuiabá) as medições do índice da intensidade da cor verde das folhas, determinado com o auxílio do aparelho CCM 200 (Opti-Sciences), considerando a leitura no terço médio de três folhas (primeira totalmente expandida) por parcela. No mesmo dia foi realizado o $2^{\circ}$ corte do capim e o mesmo foi encaminhado para o laboratório passando pelos mesmos procedimentos da primeira coleta do capim.

Os dados obtidos foram submetidos à análise de variância pelo teste $\mathrm{F}(\mathrm{P}<0,05)$ e regressão polinomial para os efeitos significativos, utilizando o programa estatístico SISVAR.

\section{Resultados e Discussão}

As doses de $\mathrm{N}$ aplicadas via foliar promoveram incremento com ajuste quadrático na produção de forragem (matéria seca da parte aérea - MS) do capim Mombaça (Figura 1). Nota-se que a maior produção de MS foi obtida com a dose de 35,24 kg ha-1 de $\mathrm{N}$, correspondendo a $1.799 \mathrm{~kg} \mathrm{ha}^{-1}$ de MS, sendo um incremento de $116,7 \%$ de produtividade, em relação ao tratamento com ausência de aplicação de $\mathrm{N}$, o qual resultou em produção de $830 \mathrm{~kg} \mathrm{ha}^{-1}$. Esse resultado demonstra a viabilidade desta forma de adubação nitrogenada em pastagens de capim mombaça. Resultados semelhantes foram observados na cultura do milho, onde a adubação foliar proporcionou aumento de $33 \%$ na área foliar em comparação à aplicação via solo (DEUNER et al., 2008). Entretanto, a adubação foliar não apresentou diferença significativa nas características agronômicas e na produtividade do feijoeiro (ALMEIDA et al., 2000).

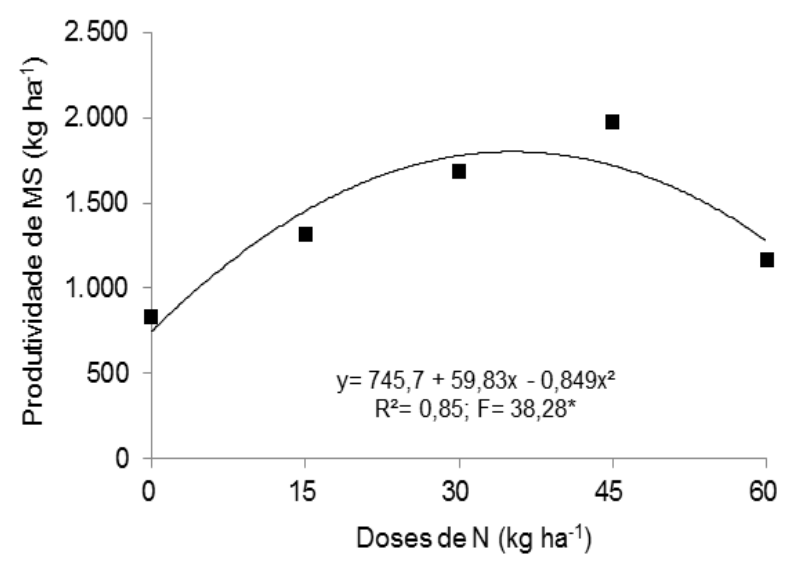

Figura 1: Produção de matéria seca da parte aérea de capim Mombaça no primeiro corte, em função da aplicação foliar de nitrogênio $(\mathrm{N})$.

$\mathrm{O}$ incremento de produtividade de forragem com a aplicação foliar de doses de $\mathrm{N}$ é devido às funções desse nutriente em diversas características morfológicas, como o tamanho das folhas e dos colmos e, também, morfogênicas, como o aparecimento e desenvolvimento de perfilhos (PATÊS et al., 2007). Vale ressaltar que a aplicação de doses de $\mathrm{N}$ muito elevadas pode resultar em queima foliar, fato observado no presente estudo com a aplicação da maior dose $\left(60 \mathrm{~kg} \mathrm{ha}^{-1} \mathrm{de} \mathrm{N}\right)$.

Houve efeito das doses de $\mathrm{N}$ na produtividade de MS do capim Mombaça no $2^{\circ}$ corte, no entanto, não houve ajuste significativo dos modelos testados $(\mathrm{RL}=$ $0,41 ; \mathrm{RQ}=0,49)$.

A aplicação de doses de $\mathrm{N}$ promoveu efeito na intensidade da cor verde da folha, resultando em aumento linear no índice (Figura 2). Tais valores ocorrem devido ao aumento da concentração de clorofila, sendo a mesma promovida por possuir maior concentração de $\mathrm{N}$ total nos tecidos. Resultados semelhantes foram obtidos com doses de $\mathrm{N}$ via solo no capim mombaça (MAZZA et al., 2009) e em xaraés, porém, em marandu e MG4, houve aumento quadrático, sendo que nas maiores doses aplicadas ao solo, a partir de $100 \mathrm{mg} \mathrm{dm}^{3}$ de $\mathrm{N}$, os teores de clorofila tenderam a estabilizar (COSTA et al., 2009).

As doses testadas não resultaram em saturação na cor verde, pois o resultado foi linear. Isto indica que doses mais elevadas proporcionariam maiores índices da cor verde, porém, deve-se atentar que na maior dose houve leves queimaduras na parte apical das folhas do capim, que provavelmente em doses mais altas poderiam se tornar maiores as lesões de queimaduras. 


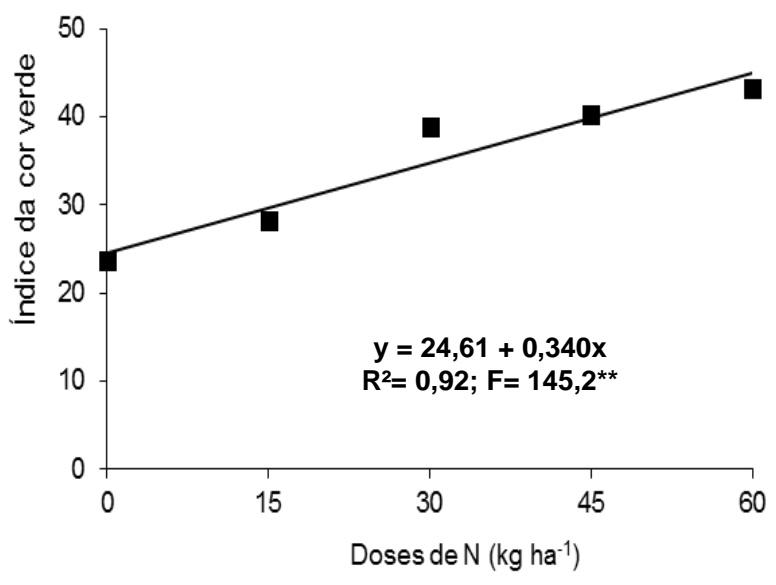

Figura 2: Índices da intensidade de cor verde da folha do capim Mombaça, em função da aplicação foliar de nitrogênio $(\mathrm{N})$.

Houve efeito das doses de $\mathrm{N}$ sobre o acúmulo de $\mathrm{N}$ e teor de proteína bruta no capim Mombaça em ambos os cortes, no entanto, não houve ajuste significativo dos modelos testados para os dados do primeiro corte.

A aplicação de $\mathrm{N}$ promoveu incremento com ajuste linear no acúmulo de $\mathrm{N}$ na parte aérea do capim Mombaça no segundo corte (Figura 3), obtendo aumento de $50 \%$ de acúmulo de $\mathrm{N}$ na maior dose em relação à ausência de aplicação de N. Resultados semelhantes foram observados em adubação nitrogenada via solo em capim Mombaça (MAZZA et al., 2009). O aumento no acúmulo de $\mathrm{N}$ explica a maior produtividade com a aplicação de doses de $\mathrm{N}$.

Para o teor de PB a aplicação de $\mathrm{N}$ promoveu incremento com ajuste linear (Figura 4), semelhante ao acúmulo de N. Este resultado comprova a importância do nutriente para a qualidade nutricional da forragem, já que este é um dos atributos de maior importância da forragem.

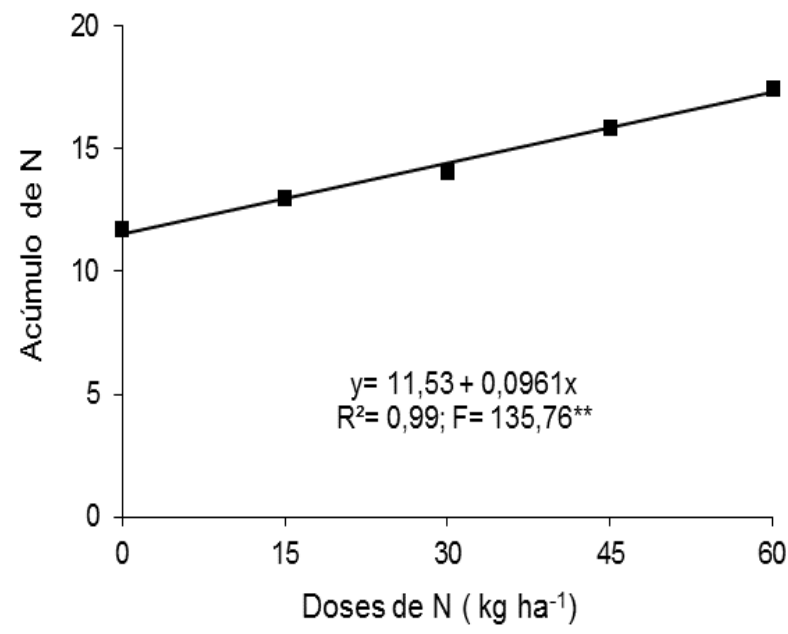

Figura 3. Acúmulo de nitrogênio na parte aérea de capim Mombaça no segundo corte em função das doses de $\mathrm{N}$ aplicadas.

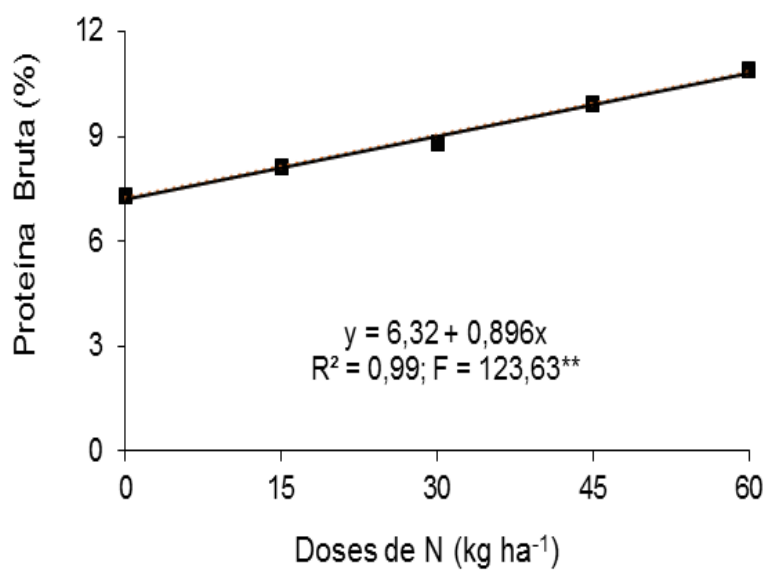

Figura 4. Teor de proteína bruta na parte aérea de capim Mombaça no segundo corte em função da aplicação foliar de nitrogênio $(\mathrm{N})$.

Com a aplicação foliar de $\mathrm{N}$ na dose de $60 \mathrm{~kg} \mathrm{ha}^{-1} \mathrm{o}$ valor de PB atingiu 10,8\%, perfazendo um aumento de 49,6\% em relação à ausência de aplicação foliar de N, a qual apresentou 7,2\% de PB. Tais valores estão próximos aos mínimos descritos na literatura (6 a 8\%) (HUMPHREYS, 1991) para não interferir no consumo e na produção, sendo que abaixo dos teores necessários poderá promover redução no consumo, induzindo a deficiência nutricional com reflexos na produção animal (DETEMANN et al., 2004).

Vale ressaltar que apesar do aumento no teor de PB com a aplicação de $\mathrm{N}$ foliar não seria dispensada a adubação via solo, pois trabalhos evidenciam teores mais elevados de PB para capim Mombaça, em que na ausência de aplicação de $\mathrm{N}$ o teor de PB apresentou valores inferiores a $8 \%$, e com a dose máxima testada de $280 \mathrm{~kg} \mathrm{ha}^{-1}$ obteve valores superiores a $10 \%$ (FREITAS et al., 2007). Em capim Brachiaria brizantha na ausência de aplicação de $\mathrm{N}$ apresentou 10,4\% de PB, e na aplicação de $400 \mathrm{~kg} \mathrm{ha}^{-1}$ de $\mathrm{N}$ via solo atingiu $16,8 \%$ (PIETROSEMOLI, 1996). Em capim Tanzânia na ausência de adubação nitrogenada a forragem apresentou valor de $8,6 \%$ de PB, sendo que com $300 \mathrm{~kg}$ $\mathrm{ha}^{-1}$ de $\mathrm{N}$ via solo parcelado em três aplicações houve um incremento na PB apresentando um valor de 12,3\% (SOUSA et al., 2010). Portanto, a adubação foliar com nitrogênio pode ser uma prática complementar importante, mas não substitui a adubação via solo.

\section{Conclusões}

A aplicação foliar de nitrogênio resultou no aumento da produção de forragem, índice da cor verde e acúmulo de N, sendo, portanto, uma importante prática complementar a adubação nitrogenada do solo.

O teor de proteína bruta foi incremento com a aplicação foliar das doses de nitrogênio, atingindo valores acima do mínimo necessário para o consumo 
animal. A aplicação foliar de $35,24 \mathrm{~kg} \mathrm{ha}^{-1}$ de $\mathrm{N}$ (ureia) foi a dose que resultou em maior produção de foragem (com $1.799 \mathrm{~kg} \mathrm{ha}^{-1}$ ).

\section{Referências Bibliográficas}

ALMEIDA, C.; CARVALHO, M. A. C; ARF, O.; DE SÁ, M.E.; BUZETTI, A. Uréia em cobertura e via foliar em feijoeiro. Scientia Agricola, Piracicaba-SP, v. 57, n. 2, p. 293 298, 2000.

CIVARDI, E. A.; SILVEIRA NETO, A. N.; RAGAGNIN, V. A.; GODOY, E. R.; BROD, E. Uréia de liberação lenta aplicada superficialmente e ureia comum incorporada ao solo no rendimento do milho. Pesquisa Agropecuária Tropical, Goiânia-GO, v. 41, n. 1, p. 52-59, 2011.

COSTA, K. A. P.; OLIVEIRA, I. P.; FAQUIN, V.; SILVA, G. P.; SEVERIANO, E. C. Produção de massa seca e nutrição nitrogenada de cultivares de Brachiaria brizantha (A. Rich) Stapf sob doses de nitrogênio. Ciência e Agrotecnologia, Lavras-MG, v. 33, n. 6, p. 1578-1585, 2009.

DETEMANN, E.; PAULINO, M. F.; ZERVOUDAKIS, J. T.; CECON, P. R.; VALADADRES FILHO, S. C.; GONÇALVES, L. C.; CABRAL, L. S.; MELO, A. J. N. Níveis de proteína bruta em suplementos múltiplos para terminação de novilhos mestiços em pastejo durante a época seca: desempenho produtivo e características de carcaça. Revista Brasileira de Zootecnia, Viçosa-MG, v.33, n.1, p.169-180, 2004.

DEUNER, S.; NASCIMENTO, R.; FERREIRA, L. S.; BADINELLI, P. G.; KERBER, R. S. Adubação foliar e via solo de nitrogênio em plantas de milho em fase inicial de desenvolvimento. Ciência e Agrotecnologia, Lavras-MG, v. 32, n. 5, p. 1359-1365, 2008.

EMBRAPA - Empresa Brasileira de Pesquisa Agropecuária. Manual de análises químicas de solos, plantas e fertilizantes. Brasília-DF: Embrapa Informação Tecnológica; Brasília, DF: Embrapa Solos, 2009. 627p.

FAGUNDES, L. F; FONSECA, D. M.; MORAIS, R. V.; MISTURA, C.; VITOR, C. M. T.; GOMIDE, J. A.; NASCIMENTO JUNIOR, D.; SANTOS, M. E. R.; LAMBERTUCCI, D. M. Avaliação das características estruturais do capim-braquiária em pastagens adubadas com nitrogênio nas quatro estações do ano. Revista Brasileira de Zootecnia, Viçosa-MG, v. 35, n. 1, p. 30-37, 2006.

FAGUNDES, J. L.; FONSECA, D. M.; GOMIDE, J. A. Acúmulo de forragem em pastos de Brachiaria decumbens adubados com nitrogênio. Pesquisa Agropecuária Brasileira, Viçosa-MG, v. 40, n. 4, p. 397-403, 2005.

FREITAS, K. R.; ROSA, B.; RUGGIERO, J. A.; NASCIMENTO, J. L.; HEINEMAM, A. B.; MACEDO, R. F.; NAVES, M. A. T.; OLIVEIRA, I. P. Avaliação da composição químico- bromatológica do capim Mombaça (Panicum Maximum Jacq) submetido a diferentes doses de nitrogênio. Bioscience Journal, Uberlândia-MG, v. 23, n. 3, p. 1-10, 2007.
HUMPHREYS, L. R. Tropical pasture utilization. Cambridge-USA: Cambridge University Press, 1991. 206p.

JONES, D. B. Factors for converting percentages of nitrogen in foods and feeds into percentages of protein. Washington-USA: United States Departament, (Circular, 183), p. 1-21, 1931.

MACEDO, M. C. M. Integração lavoura e pecuária: o estado da arte e inovações tecnológicas. Revista Brasileira de Zootecnia, Viçosa-MG, v. 38, n.1, p. 133-146, 2009.

MALAVOLTA, E. Manual de nutrição mineral de plantas. Piracicaba-SP: Editora Ceres, 2006. 631p.

MAZZA, L. M; PÔGGERE, G. C.; FERRARO, F. P; RIBEIRO, C. B. CHEROBIM, V. F.; MOTTA, A. C. V.; MORAES. A.; Adubação nitrogenada na produtividade e composição química do capim mombaça no primeiro planalto paranaense. Scientia Agraria, Curitiba-PR, v. 10, n. 4, p. $257-$ $265,2009$.

MELlO, A. Q. S.; FRANÇA, A. F. S.; LANNA, A. C.; BERGAMASCHINE, A. F.; KLIMANN, H. J.; RIOS, L. C.; SOARES, T. V. Adubação nitrogenada em capim-mombaça: produção, eficiência de conversão e recuperação aparente do nitrogênio. Ciência Animal Brasileira, Goiânia-GO, v. 9, n. 4, p. 935-947, 2008.

PATÊS, N. M. S.; PIRES, A. J. V.; SILVA, C. C. F. SANTOS, L. C.; CARVALHO, G. G. P.; FREIRE, M. A. L. Características morfogênicas e estruturais do capim-tanzânia submetido a doses de fósforo e nitrogênio. Revista Brasileira de Zootecnia, Viçosa-MG, v. 36, n. 6, p. 1736-1741, 2007.

PRIMAVESI, O.; PRIMAVESI, A.C.; CORRÊA, L.A.; SILVA, A. G.; CANTARELLA, H. Lixiviação de nitrato em pastagem de coastcross adubada com nitrogênio. Revista Brasileira de Zootecnia, Viçosa-MG, v. 35, n. 3, p. 683-690, 2006.

PIETROSEMOLI, S.; GERARDO, L.; VILLALOBOS, N. Respuesta del pasto Bracharia brizantha a la fertilización nitrogenada. Revista de la Facultad de Agronomía, LuzCOL, v. 13, n. 5, p. 551-560, 1996.

ROCHA, P. G.; EVANGELISTA, A. R.; LIMA, J. A.; ROSA, B. Adubação nitrogenada em gramíneas do Gênero Cynodon. Ciência Animal Brasileira, Goiânia-GO, v. 3, n. 1, p. 1-10, 2002.

SOUZA, E. M.; ISEPON, O. J.; ALVES, J. B.; BASTOS, J. F. P.; LIMA, R. C. Efeitos da irrigação e adubação nitrogenada sobre a massa de forragem de cultivares de Panicum maximum Jacq. Revista Brasileira de Zootecnia, Viçosa-MG, v. 34, n. 4, p. 1146-1155, 2005.

SOUSA, R.S.; PIRES, A.J.V.; CARVALHO, G.G.P.; SILVA, F.F.; MAGALHÃES, A.F.; VELOSO, C.M. Composição química de capim-tanzânia adubado com nitrogênio e fósforo. Revista Brasileira de Zootecnia, Viçosa-MG, v. 39 n. 6, 2010. 